\title{
11. Designing for Transfer
}

\author{
Mette Wichmand
}

\begin{abstract}
How can a game design support the transfer of human resources from an in-game world to the physical world? A possible answer can be found in the in-depth case study of the World Bank's game Urgent Evoke presented in this chapter. Urgent Evoke is a game designed to empower players to become post-game social innovators, and this chapter shows how the winners' interaction with and sense-making of the game enabled a successful transfer to and implementation of their ideas in the physical world. The analysis is based on activity theory and leads to a discussion of how an understanding of the successful transfer strategies of the winners can inspire future game designs and strengthen the transfer process.
\end{abstract}

Keywords: game design; transfer; empowerment; social innovation; activity theory

\section{Background}

The gaming industry has diversified its means of expression over the years. Today, digital games can be played alone; with a friend; or with thousands of strangers; simultaneously or not; via a computer, tablet, or mobile phone; at home or on the go. A game can be filled with words or may offer a simple ${ }_{2} \mathrm{D}$ interface or a $3 \mathrm{D}$ immersive virtual world. It can let you play with reality as you know it or take you to new or historical environments or even to a fantasy world for you to explore. It can take a minute to play or as many hours and days as you choose. The possibilities are therefore endless, and this has led to games being produced, used, and seen not only as tools for entertainment but also as persuasive mediums that 'like the protected books, plays, and movies that preceded them [...] communicate ideas - and even social messages - through many familiar devices (such as characters,

Hera, T. Dela, J. Jansz, J. Raessens, B. Schouten, Persuasive Gaming in Context. Amsterdam: Amsterdam University Press, 2021 DOI 10.5117/9789463728805_CH11 
dialogue, plot, and music) and through features distinctive to the medium (such as the player's interaction with the virtual world)' (Brown, Governor of California, et al. v. Entertainment Merchants Association et al., Supreme Court of the United States, 27 June 2011).

The World Bank's social innovation game Urgent Evoke is a state-of-the-art example of a persuasive game. What's interesting about a game like this is that it not only aims to communicate ideas and social messages, it also makes the claim that playing the game will enable players to transfer the knowledge, ideas, and other resources found and constructed in the game to the physical world, enabling them to become post-game social innovators capable of wrestling with some of the world's most serious problems, e.g., poverty and hunger. If and how this transfer is enabled by the game design and the players' use of the game is the core issue in this chapter.

\section{Urgent Evoke}

Urgent Evoke (UE) is an online social network game that's free to play via a computer, tablet, or smartphone. The game was developed by the World Bank Institute and game designer Jane McGonigal. Its aim, as noted above, is to generate post-game, player-driven social innovation.

UE was played for the first time in 2010 over a ten-week period. The game was open to players of all ages and could be played anywhere in the world. Today, the original game can still be found online but is now only available to high school teachers as an educational tool.

UE revolves around a narrative told in the form of a graphic novel. A new chapter was released each week. The narrative driving the game tells the story of a secret international network of agents with innovative superpowers capable of solving some of the world's most serious problems (hunger, armed conflict, environmental challenges, etc.). Players take on the role of agents in the network and are given a new mission each week. The missions are connected to the serious problems presented in the ten chapters of the graphic novel. The tasks are formulated to help players reflect upon and strengthen their personal capacity as a social innovator.

To win the game, players had to complete ten missions and ten quests and turn in an Evokation. An Evokation is a detailed and innovative plan of how the player will tackle a self-chosen challenge in the physical world after the game has ended. The World Bank evaluated the Evokations, and the plans found to be the most promising were rewarded with a mix of seed money, mentorships by respected social innovators and entrepreneurs, and 
an opportunity for the winners to attract crowd funding via the Global Giving Challenge (www.globalgiving.org/evoke). A subset of winners was also invited to a post-game EVOKE summit held in Washington, DC.

Along with the winners, players who completed all ten missions and quests were recognized for their engagement and received World Bank Institute certificates stating that they are certified social innovators. Their names are mentioned on the UE website as 'Certified EVOKE Social Innovators - Class of 2010'. Players who completed one or more missions and quests were recognized on the UE website as one of 'the EVOKE class of 2010 graduates'.

During the initial ten-week run-time in 2010, UE attracted unprecedented public attention for a serious game: 171,958 different individuals made 286,219 visits to the game; 19,386 people registered as players; 6,618 people completed at least one mission or quest; 142 players completed all ten missions and quests; 73 people submitted Evokations; and 32 Evokations were awarded by the World Bank (Gaible \& Dabla, 2010). The game's intention to empower the players was built into and communicated through all parts of its design.

One of the ways it did this can be found in the designers' blurring of the line between the in-game world and the physical world. UE offered its players a safe, artificial space where the rules of the physical world were, in some ways, vaporized. Inside this 'magic circle' (Huizinga, 1955), it was possible to play the role of a social innovator with superpowers and come up with bold, innovative ideas without being afraid that millions are being lost or people are dying of hunger if your idea turned out to be more creative than sustainable. Yet the magic circle of UE was also designed to give players a sense of reality. Castronova (2005) talks about how the magic circle of a game can be perforated, which, as a result, enables the online and offline realities to mix. In UE, the design was made to open up for players' social fantasies by including them in the make-believe of the narrative. At the same time, the design was also intended to provide players with the experience of being a social innovator. This was achieved by letting them 'play' with real world problems, asking them to use their real name, telling them that this is 'for real', and asking them to not only learn and imagine but also act throughout the game and produce a detailed plan for post-game action. In that sense, the game prepared players for a future as a social innovator while also offering a safe space to practice.

Another way that UE was designed for empowerment is that the game offered a goal-oriented structure or process where actionable next steps paved the way to success, and tokens were on offer (badges, power points, and awards) for completed missions. Players were also offered a great deal of 
freedom to shape their own game, as the game had very few explicit rules and the severity of the problems dealt with ensured a high level of uncertainty. This means that there was no one right answer to the problems, just an infinite number of possible solutions. The narrative, along with the missions and quests, was designed to ensure that the players knew what to do next. As the game developed and the missions and quests became tougher, the players could also experience themselves becoming increasingly proficient. In other words, the players began to grow and develop as social innovators.

A third and very central way in which UE's design supported player empowerment was the manner in which the game facilitated the forming of a social network among its players. This was done through the narrative of the game, which told players that social innovation requires teamwork; through the complexity of the missions, which led players to collaborate; and by facilitating player communication via the discussion forum and players' personal pages. As the game developed and players started to befriend each other, a network emerged that was transferrable to the physical world and enabled them to share ideas, knowledge, and other resources.

\section{Methodology and methods}

The data presented in this chapter stem from an in-depth single case study of UE. The study is based on a mixed-method approach, and the methods used are:

- non-participatory observations on the UE site after the game ended;

- a document analysis of an evaluation report on UE, written by the Natoma Group for the World Bank;

- open and semi-structured qualitative interviews conducted via email and Skype with twelve winners of UE as well as one face-to-face interview with Robert Hawkins, senior advisor at the World Bank and executive producer of the game;

- a social network analysis of the players' in-game social network, which was conducted using the NodeXL software.

The aim of the case study was to produce a rich, context-dependent description of a game that provides a nuanced insight into how the game design enabled its players to become post-game social innovators. The ontological starting point for this research is that it is impossible to capture one 'true' social reality because the social world only shows itself through representations or interpretations and because no one experiences or interprets things 
in the same way. It is therefore necessary to operate with a pluralistic concept of reality (Denzin, 2012; Greene, 2012; Pearce, 2012). The epistemological consequence of this pluralism is that the knowledge created about the social world should be seen as an interpretation, i.e., a construction, or one story among several possible stories. In such a constructivist, ontological, and epistemological framework, the aim of the researcher is not to produce 'truth' but to bring 'breadth, complexity, richness, and depth to any inquiry' (Denzin, 2012). Such an imperative calls for a methodology that makes room for multiple voices, differences, and dialogue. The methods chosen for the case study are qualitative and quantitative. Together, they represent different ways of looking at the same phenomenon and different voices (Denzin, 2012).

In the analysis, the participants are given pseudonyms when they are quoted. This is not so much to hide their real identity but to underline that the analysis should be seen as the author's interpretation and not necessarily as the opinions of the respondents.

\section{Theory}

The analysis is based on the third generation of activity theory (3GAT) (Engeström, 1999; Engeström, 2001, 2008; Engeström, Engeström \& Kärkkäinen, 1995; Engeström, Miettinen \& Punamäki, 1999; Engeström \& Sannino, 2010). AT is a social-learning theory based on the idea that the interplay between humans and technologies or mediating artifacts creates a dialectic relationship that drives cognitive, emotional, and material development.

AT should be seen as an evolving 'philosophical and cross-disciplinary framework for studying different forms of human practices as development processes, both individual and social levels interlinked at the same time' (Kuutti, 1996).

The first generation of AT (1GAT) was produced by Vygotsky (1896-1934). His idea was that activities are the key to understanding human development and that activities involve the use of mediating artifacts. The second generation of AT (2GAT) builds on the work of Vygotsky's student, Leont'ev. Leont'ev added a social aspect — community — to the theory, as he thought that human activities and learning always takes place in communities where there is a division of labor among the participants and the interaction is guided by a set of social rules. Engeström's 3 GAT provides the theory with a network perspective-connecting different activity systems to each other. The connectedness enables a discussion of how learning and development in one system can be transferred to another activity system. 


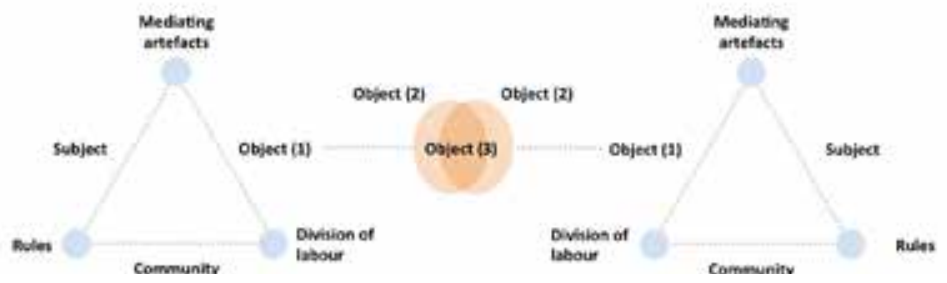

Figure 11.1: Reproduction of a 3GAT model from Engeström (2001:136).

Engeström's 3GAT can be visualized in the following way:

Engeström's 3GAT is a learning theory, but it could also be seen as an innovation theory because the focus is on the meeting of at least two activity systems where a new third and shared object is created through negotiations between the systems. This negotiation process of a new third object could be seen as a process of innovation-or at least as a process that has the potential for innovation. The new third object is placed outside and in between what could be called 'the original activity systems' and is shaped by the previous learning and goals of the activity systems involved. The third object stands in a dialectical relationship with the 'original' activity systems because it reflects back on the systems involved and influences them. With Engeström, activity systems are embedded in larger structures where new objects are created and mutual influence takes place.

Engeström's 3GAT model is interesting in relation to UE and this chapter because it enables a discussion of how the game permitted a transfer of resources from the game as an activity system to the players' post-game activity systems in the physical world. UE's goal was to empower the winners in a way that enabled them to implement their ideas in the physical world after the game ended. From a 3 GAT perspective, this means that the winners should be able to identify another activity system and be willing to negotiate a new third and shared object based on their Evokations.

\section{Analysis}

The following analysis focuses on the moment of transit and the post-game situation, where the winners have to transfer the resources from the game to the physical world and start implementing their ideas. The analysis will focus on the winners whose transfer process succeeded, but before doing so, the context of the transfer situation will be sketched using $3 \mathrm{GAT}$. 


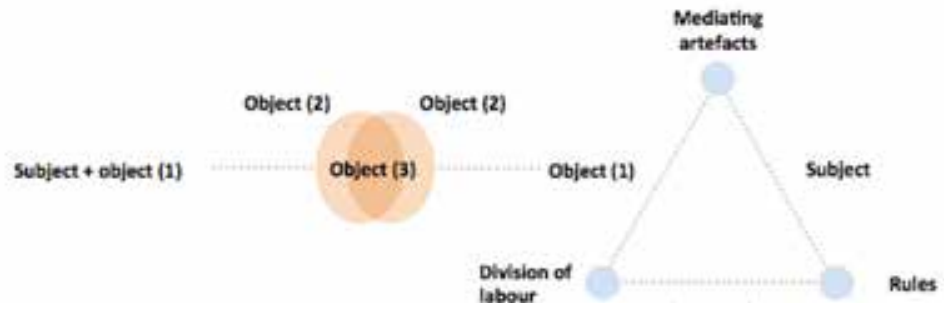

Figure 11.2: Visualization of an activity theory understanding of the post-game situation of the winners of Urgent Evoke.

\section{Game over}

When UE ended, all the players, including the winners, had to leave the game. This meant that the winners were supposed to start implementing their Evokations without having access to a platform that could host their community and facilitate their collective activities. The winners were therefore left in a vulnerable situation without the structure, resources, and community of the game at the precise moment when they were expected to act as social innovators in the physical world. An activity theory-inspired drawing of the situation could look like this:

Engeström's original model depicts a meeting between two activity systems. However, in the case of UE, the winners were left to their own devices when it came to trying to negotiate a new third object with an entire activity system. This could be understood as a moment of disempowerment, and the inequality makes it understandable that some of the winners did not manage to transfer their Evokation to the physical world.

The following analysis builds on the interviews conducted with the winners of UE. Thirty-two players won the game. Of them, eighteen have been traced and interviewed. Ten of the eighteen succeeded in turning their ideas into reality to varying extents. Of the ten successes, three that illustrate how the game design supported the players' transfers have been chosen for this chapter: the stories of Axel, William, and Jonas.

\section{Transferring self-confidence}

Axel describes himself as an introverted white man from Zimbabwe who has always had the feeling that he should change the world for the better but didn't dare say it out loud. In UE, Axel met like-minded people and it suddenly felt okay to state his desire to become a social innovator. At the end of the game, Axel decided to turn in an Evokation. As he is a programmer, his 

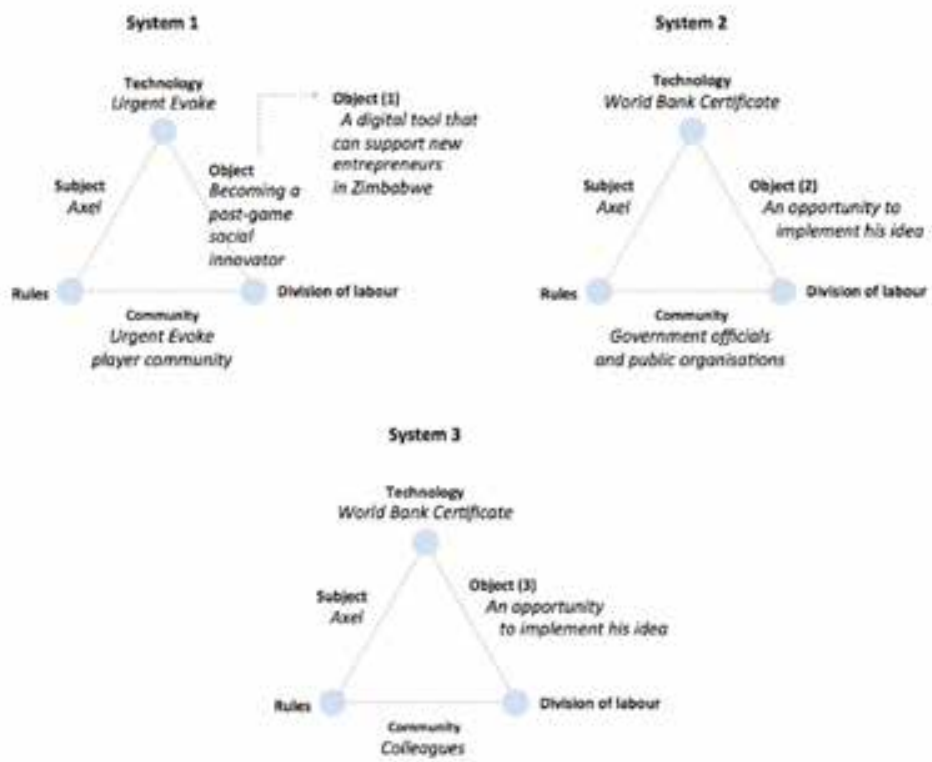

Figure 11.3: Visualization of Axel's in-game and post-game work.

idea was to produce an IT platform that could help people build their own business by creating an eco-system online where they can learn, collaborate, and build a new social network.

Post-game, Axel visited an ICT conference run by a ministry in Zimbabwe. Here, he told the other participants that he was an accredited World Bank social innovator. Mentioning this accreditation gave him access to the minister and a chance to present his Evokation. Today, Axel works for the government implementing his Evokation in a renegotiated form, where the aim is to create a digital platform where prisoners can get the support needed for them to develop business ideas and a way out of a life of crime. There is no doubt in Axel's mind that he would not be doing what he is today if it were not for UE:

[...] personally I found it [the game] builds up your confidence thatyou do have a voice and you can actually make a change. I don't think I would have had the confidence to approach the prisons and do the work projects that I'm doing now if I hadn't been through Evoke. (Axel)

Visualizing Axel's in-game and post-game work produces the following:

From a 3 GAT perspective, Axel made a successful transfer from the game to the physical world because he was capable of identifying another activity system (the prisons) that had an interest in his idea and because 
he managed to become a member of the prison activity system. He brought his object with him, which he modified to fit this system. UE empowered him by providing him with a safe space where he could practice his voice and develop the self-confidence needed to say out loud that he was capable of creating social change. Furthermore, Axel brought with him the World Bank certificate stating that he is a social innovator. Even though it had been earned in a game, this had a recognizable value outside the game and was a key to a new activity system.

\section{Transferring the object to new activity systems}

William is African and his Evokation is about starting a demo-farm where local farmers can try out new technologies and build up new knowledge that can develop and strengthen local agriculture. As well as playing UE, William is also busy with his education and knows that he can't work full time on his Evokation. He therefore had to pass it on to another activity system. However, as the game has ended, he can't find a system that has the resources or the structure needed to implement his idea. William's first challenge was therefore to raise money through the Global Giving competition:

You should have a good network to be able to get funding, to get people to donate to your cause, especially in the initiate stage, [...] I didn't have [this] at the time, so I tried to use Twitter and Facebook [...] asking people to donate to the cause [...] I think overall I got about [...] seven hundred something dollars. But then Istill had to get the extra one thousand from the World Bank [...] so I was good. Many people, well not many people but some people, managed to get to the next round [...] That's something I didn't manage to do because of my network at the time [....] (William)

William struggled to raise money for his project, just like other players, and he succeeded not because he had a large social network that he could draw on but because he used alternative technologies like Facebook and Twitter that allowed him to reach people outside his personal network.

I looked at it as, you know, in a way it was about fundraising and also trying to sellyour idea to people and see how people would respond to that. I had many random donors, which was really interesting to see; people just donating to a cause and I didn't even know them. I had some friends donating, and it was also really interesting to see that friends could really believe in my cause. It's also like a very rare thing to get people here to donate to an online cause [...] and also a lesson that I learned from that is I've been able to do many drives, like fundraising drives locally, but all my experience has been drawn from what I learned from the game. (William) 
For William, UE was more a learning experience than an entertainment technology, and the learning that began in the game can be transferred to the physical world. In William's view, there is no boundary between the in-game and out-game situation. Instead, there is a common thread running from William's experiences in the game to what he learned afterwards, because these experiences continued to form the basis for more learning post-game. He seemed surprised about what he was able to achieve, and his positive experience of winning the game seemed to be reinforced by him getting both strangers and friends to donate online to his project.

After the Global Giving contest, William knew that he didn't have enough money to start the demo-farm described in his Evokation. Instead, he approached a women's farming group in his local environment. He wanted to see what they would do if they got the thousand dollars he had raised. Together, they came up with an idea of micro-loans for local female farmers. The women weren't as organized as William would have liked them to be, but together they developed a structure to assess whether a loan applicant was eligible or not.

They had a group, which was, I would say, not very active in terms of coming together, planning together, cooperating, and what I wanted to achieve with my project was to see a women's group that really works together [....] From my childhood I learned that money is something that brings people together, but it can also separate them. So [...] being able to give people these small loans would bring them together, because every time someone wanted the money, they would come to the group and say, 'Look, I want to grow beans', and they would say, 'How much beans do you want to grow?', and they would say, 'Probably if you give me enough to buy ten kilos, I would be happy', and they would say, 'Doyou have the land?', and they say, 'Yes', and then they would say, 'Okay, first we come and inspect your land then we would...'. So eventually, it would turn out that they get more info and then in a way they keep following up from time to time and for me that was something that I really wanted to see and it's exactly how they are taking it on. (William)

Looking at William's story with 3 GAT, it's clear that he's aware that he needs an activity system to implement his Evokation successfully. He has chosen to collaborate with a network he already knows. He was also willing to let go of his original idea and instead negotiate with the women about how the funding he raised could best be put to use. Through the negotiations, William and the women managed to create a new shared third object - providing micro-loans to female farmers. What's more, during the negotiations, the women's network began to resemble an activity system with an object, rules, and a division of labor. 

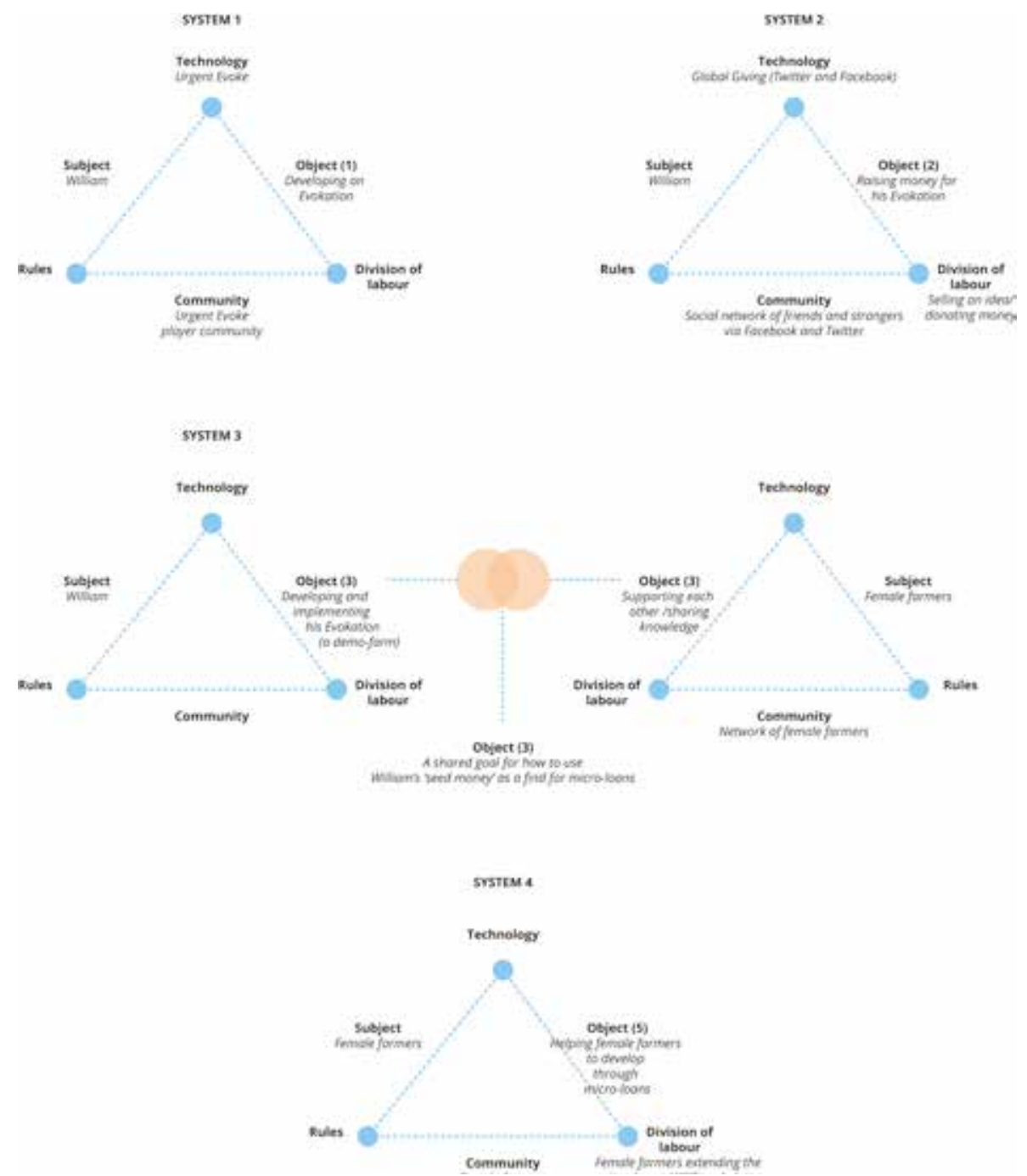

Figure 11.4: Visualization of William's in-game and post-game work.

The following sketch shows William's in-game and post-game situations. Again, no negotiation took place between the two activity systems postgame, but William managed to construct a new activity system around a new third object.

As well as helping him become aware of his own capacity as a social innovator and fundraiser, William gained from the game an understanding of the structures and level of collaboration needed for a social network like that of the women farmers to be able to function as the learning community that he would have liked his demo-farm to be. 


\section{Continuing the development process}

Jonas's story starts with him and some other players deciding to work together on the implementation of their ideas from the game. This could be seen as an attempt to create a new activity system based on the old player community, but the collaboration did not last that long:

I guess because we [...] didn't see the immediate feedback that we got in the game, like 'you did this - great!' and you know, like points and people encouraging you. It was like everyone lost momentum and then we [...] lost coordination and plus this, there wasn't a very clear vision of what needed to be done. (Jonas)

Jonas describes how the group lost momentum because the instant feedback from other players and the clear goal structure of the game were no longer there. Yet losing momentum with the group of former players didn't stop Jonas. He kept working on his own Evokation, which was focused on urban gardening. He experimented on his own rooftop. After some time practicing, he began helping friends to build their own rooftop gardens. He used his offline social network to build a community around his idea and, through this network, disseminated his vision and know-how.

After some time, Jonas got a new job and had to move to another part of the country. Moving meant a change of scenery, and Jonas found himself in a situation where he had to relearn his newly established urban farming skills and build a new social network:

$[. .$.$] the weather's very different from here, so everything changes; I had to$ re-learn a lot of the things I'd learned. But it was good in another sense because I met people there and I learned how to grow this there in that weather and stuff like that (Jonas).

Jonas learned how to farm in new weather conditions, and he also managed to build a new community. He started to dream bigger dreams based on these positive experiences:

I have another project right now, [...] and I think it's learning a lot from these experiences and it's expanding a lot; it's not going to be only about urban farming; it's going to be about the May Cube Movements, you know, like in a broad sense like farmers, and people doing urban farming, and people doing ${ }_{3} D$ printing, and people doing crafts, you know, trying to learn from this lesson and try to keep going. (Jonas)

Since UE, Jonas has gone through several learning experiences, a process he described in the following way: 

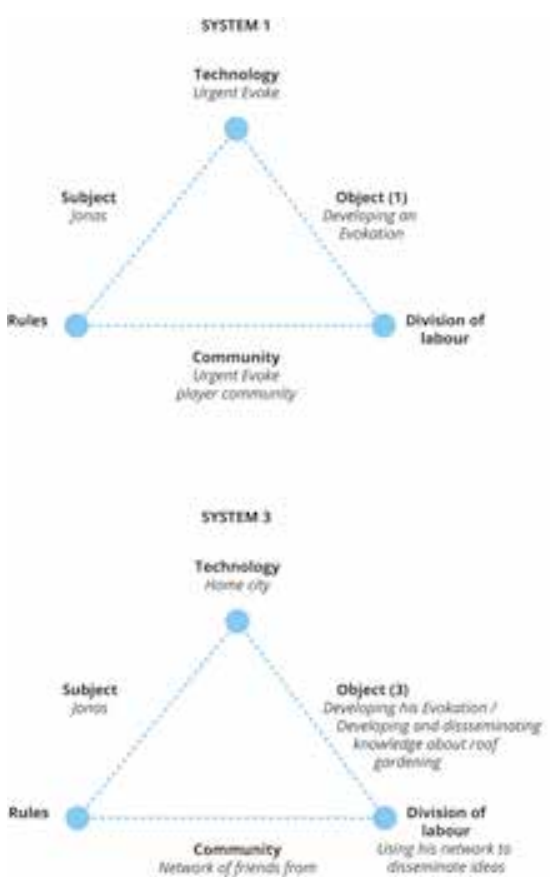
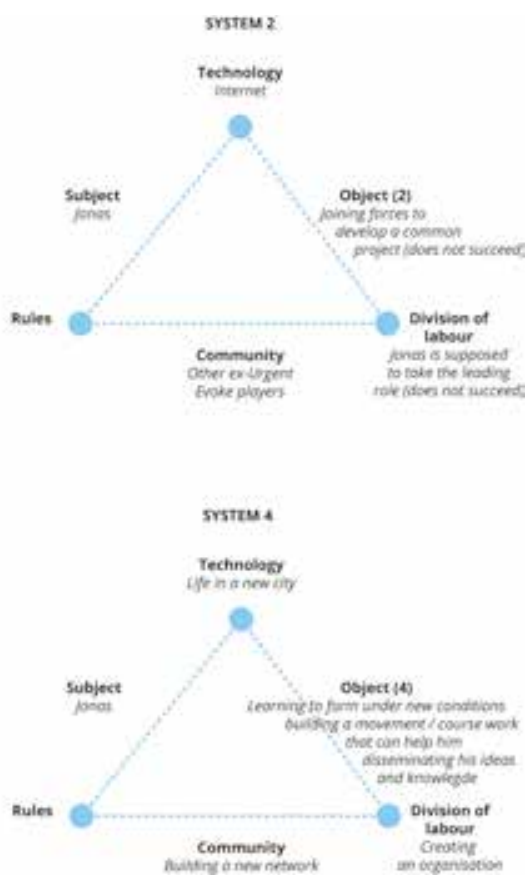

Figure 11.5: Visualization of Jonas's in-game and post-game work.

I see it as three steps; first, I learned a lot in Urgent Evoke; second, I learned a lot with my own project thanks to Urgent Evoke and then, hopefully, I will take all those lessons into this project. (Jonas)

As with many of his game colleagues, Jonas's way of handling the implementation of his Evokation also calls for changes in Engeström's model:

From a 3 GAT perspective, Jonas's process indicates that he transferred elements that he met through the UE game to his own post-game process. He was aware that he needed to build up both the core skills required to be an urban gardener and a social network to help him disseminate his knowledge and ideas. UE provided him with a way to handle his own developing process as a social innovator, which was an approach that allowed him to expand his confidence, skills, and ideas step by step:

So it [the game] has taken me from how I saw myself there [...] to someone that can have a larger impact. [...] I think that's so nice, [...] I haven't said this out loud, but I'm thinking about it, and it's such a nice change [...] in my own perception of myself. So now I do believe I'm a social innovator [...] Maybe I knew before that I had an impact on a smaller scale [...] but not in such a large scale and with subjects that aren't necessarily related to what I went to school for. (Jonas) 


\section{Conclusion}

At the start of this chapter, Figure 8.1 depicts Engeström's third generation activity theory (3GAT). As noted then, the model provided a framework for understanding how players could move from an in-game to a post-game situation and in so doing conduct a successful transfer of knowledge and resources from the game to the physical world.

Yet, as the analysis has shown, the post-game reality of the players did not mirror the theoretical model because the empowering structure of the game vanished when it came to an end. This meant that the players lost the activity system that had supported their development as social innovators at the time when they should have been starting to perform this role offline. Designing the game to end at this crucial point in the players' development process created a situation of disempowerment and made it even more difficult for the winners to conduct the intended transfer of resources and ideas from the game to the physical world. Despite this, however, the analysis has also shown that some of the winners still managed to implement their Evokation post-game, e.g., Jonas's urban gardening project, William's network of female farmers, and Axel's digital platform for prisoners with business ideas.

What is common to the winners who succeeded post-game is that even though UE as an activity system ceased to exist, the players felt that they had received attention and social recognition from the player community during the game, which gave them the courage and desire to see themselves as post-game social innovators, to believe in their own voice and ideas, and to continue developing their ideas and themselves post-game.

The winners interviewed not only gained self-confidence and a learning capacity from the game but also ideas, a social network, a World Bank certificate stating that they are certified social innovators, seed money and money from the Global Giving crowd-funding competition, and maybe also a personal mentor. All these are social and material resources that supported their post-game endeavours.

Together, these mental, social, and material resources that were transferred from the game to the physical world played an important role in the empowerment of the winners. Yet the analysis highlights one other very important thing that the players seem to have taken with them from the game, namely an understanding of how social innovation needs to be embedded in an activity system in order to take off. Looking at the winners' interviews and their post-game strategies, it's possible to recognize in all of them a systemic understanding of human learning and development. This 
can be seen in Jonas's way of building his project in stages, starting with friends in his home town and ending with a network of total strangers in a new city, and in William and Axel's ways of identifying existing networks that could adopt their idea or within which they could develop their idea further.

In conclusion, it's clear that UE teaches us that, in order for a game design to facilitate the transfer of resources from the online to the offline world and thereby empower players to become post-game social innovators, it's not enough to produce a design that provides players with access to a mix of mental, social, and material resources; the game must also be designed to be an exemplary learning environment where the design itself works as a form of meta-communication that shows the players what social structures and systemic elements are required to enable citizen-driven social innovation. In addition, UE highlighted the need to recognize the game as an activity system equal to an activity system in the physical world. This means that games should not be designed to end at the precise moment the players are being asked to transfer their ideas to the physical world. Instead, we should think of games as infinite platforms to which players can return and reconnect with the resources made available to them throughout the game. Indeed, by keeping UE alive, the design would have provided its winners with support in the difficult transfer process.

\section{References}

Castronova, E. (2005). Synthetic Worlds: The Business and Culture of Online Games. Chicago, IL: University of Chicago Press.

Clark, V.L.P., \& Creswell, J.W. (2007). Designing and Conducting Mixed Methods Research. Thousand Oaks, CA: Sage Publications.

Connolly, T.M., Boyle, E.A., MacArthur, E., Hainey, T., \& Boyle, J.M. (2012). A Systematic Literature Review of Empirical Evidence on Computer Games and Serious Games. Computers \& Education, 59(2), 661-686. doi:10.1016/j.compedu.2012.03.004.

Costikyan, G. (2002). I Have No Words \& I Must Design: Toward a Critical Vocabulary for Games. In F. Mäyrä (ed.), Computer Games and Digital Cultures Conference Proceedings, pp. 9-35. Tampere, Finland: Tampere University Press.

Denzin, N.K. (2012). Triangulation 2.o. Journal of Mixed Methods Research, 6(2), 8o-88. https://doi.org/10.1177/1558689812437186.

Dervin, B. (1998). Sense-Making Theory and Practice: An Overview of User Interests in Knowledge Seeking and Use. Journal of Knowledge Management, 2(2), 36-46. https://doi.org/10.1108/13673279810249369. 
Donovan, T., \& Garriott, R. (2010). Replay: The History of Video Games. Lewes, England: Yellow Ant.

Engeström, Y. (1987). Learning by Expanding: An Activity-theoretical Approach to Developmental Research. Helsinki: Orienta-Konsultit Oy.

- (1999). Communication, Discourse and Activity. Communication Review, 3(1-2), 165-185. https://doi.org/10.1080/10714429909368577

- (2001). Expansive Learning at Work: Toward an Activity Theoretical Reconceptualization. Journal of Education and Work, 14(1), 133-156. doi: $10.1080 / 13639080020028747$.

. (2008). From Teams to Knots: Activity-Theoretical Studies of Collaboration and Learning at Work. New York, NY: Cambridge University Press.

—, Engeström, R., \& Kärkkäinen, M. (1995). Polycontextuality and Boundary Crossing in Expert Cognition: Learning and Problem Solving in Complex Work Activities. Learning and Instruction, 5(4), 319-336. https:/doi. org/10.1016/o959-4752(95)ooo21-6.

— Miettinen, R., \& Punamäki, R.L. (eds.) (1999). Perspectives on Activity Theory. Cambridge: Cambridge University Press.

— \& Sannino, A. (2010). Studies of Expansive Learning: Foundations, Findings and Future Challenges. Educational Research Review, 5(1), 1-24. https://doi. org/10.1016/j.edurev.2009.12.002.

Gaible, E. \& Dabla, A. (2010). EVOKE Project Evaluation. Retrieved 11 June 2018 from www.siteresources.worldbank.org/EDUCATION/Resources/ProjectEvokeevaluation-final-16oct11.pdf.

Greene, J.C. (2012). Engaging Critical Issues in Social Inquiry by Mixing Methods. American Behavioral Scientist, 56(6), 755-773. https://doi. org/10.1177/0002764211433794.

Huizinga, J. (1955). Homo Ludens: A Study of the Play-element in Culture (2014 ed.). Eastford, CT: Martino Fine Books.

Kuutti, K. (1996). Activity theory as a potential framework for human-computer interaction research. In B.A. Nardi (ed.). Context and consciousness: Activity theory and human-computer interaction, pp.17-44. Cambridge, MA: MIT Press.

Law, J., \& Urry, J. (2004). Enacting the Social. Economy and Society, 33(3), 390-410. https://doi.org/10.1080/0308514042000225716.

Mertens, D.M. (2012). What Comes First? The Paradigm of the Approach? Journal of Mixed Methods Research, 6(4), 255-257. https://doi.org/10.1177/ 1558689812461574 .

Yin, R.K. (2009). Case Study Research: Design and Methods. Thousand Oaks, CA: Sage Publishing. 


\section{About the author}

Mette Wichmand is an Assistant Professor in the Department of Communication and Arts at Roskilde University in Denmark. Mette's research is concerned with how to build and sustain communities online with the purpose of generating civic engagement and social change. She is currently researching how social network games can empower players to become post-game social innovators. 
